\title{
Livro de combate: 0 caso Em câmara lenta e sua repercussão pública no contexto da ditadura civil- militar
}

\section{Combat book: the case Em câmara lenta and its public repercussion in the context of the civil-military dictatorship}

https://doi.org/10.34112/2317-0972a2017V35n71p49-72

\section{Mário Augusto Medeiros ${ }^{1}$}

RESUMO: Analisam-se as condições sociais de produção e recepção da obra Em câmara lenta, de Renato Tapajós, publicada em 1977 pela editora Alfa-Ômega, em São Paulo. Esse romance foi um dos primeiros livros escritos por um guerrilheiro urbano, logo que liberto do Presídio Tiradentes. Também foi um caso estridente de censura da ditadura civil-militar, imediatamente após a publicação da obra, que mobilizou diferentes agentes nacionais e internacionais.

Palavras-chave: Censura; ditadura civil-militar; Em câmara lenta.

ABSTRACT: The social conditions of production and reception of the book Em câmara lenta, by Renato Tapajós, published in 1977 by the Alfa-Omega publishing house in São Paulo, are analyzed in this text. This novel was one of the earliest books written by an urban guerrilla member as soon as he was released from the Tiradentes Prison. It was also a strident case of censorship by the civil-military dictatorship, immediately after its publication, which mobilized different national and international agents.

KeYwords: Censorship; civil-military dictatorship; Em câmara lenta.

1. Universidade Estadual de Campinas, Campinas, SP, Brasil. 
Livro de combate: $O$ caso Em câmara lenta e sua repercussão pública no contexto...

\section{INTRODUÇÃO}

Um livro é um complexo de relações sociais. O objeto encerra em si diferentes linhas de força que o tornaram possível, além do motor inicial - a potência do autor em fabulá-lo ao mundo. Desde a capa (com a concepção gráfica), o uso de imagens ou não, os tipos empregados para explicitar o título e a forma como o nome de autor aparece - esse nome de autoridade e responsabilidade, pelo qual um sujeito passou a ser alvo de interdições e censuras (FOUCAULT, 1992) -; a presença dos textos de contracapa, orelhas e outros dados são todos elementos que antecedem a própria leitura do conteúdo. São elementos formais que se apresentam como possibilidades analíticas para cientistas sociais e historiadores interessados nas condições sociais de produção de uma obra.

Este é o ponto de partida que será empregado neste artigo. Analisam-se as condições sociais de produção e recepção da obra Em câmara lenta, de Renato Tapajós, publicada em 1977, em São Paulo. O romance, publicado pela editora Alfa-Ômega, foi um dos primeiros livros escritos por um guerrilheiro urbano, logo que liberto do Presídio Tiradentes. Também foi um caso estridente de censura da ditadura civil-militar, imediatamente após a publicação da obra, que mobilizou diferentes agentes nacionais e internacionais.

O livro, classificado de subversivo, foi analisado por censores da polícia política, apreendido, proibido. E seu autor, novamente preso, objeto de disputa dos sentidos da produção da obra, dos efeitos de verossimilhança e uso social da mensagem que Em câmara lenta poderia produzir.

Além disso, tanto autor como obra foram levados aos bancos dos tribunais, tendo sido necessário contar em sua defesa, dentre outros elementos, o parecer como perito do sociólogo e crítico literário Antonio Candido de Mello e Souza (1918-2017), convocado pelo advogado de Tapajós, Aldo Lins e Silva. Ao defender o livro de Tapajós, defendia-se a liberdade de expressão da arte, a memória dos atingidos pela ditadura e que lutaram contra ela. 
MEMórias DA GUERRILHA URBANA
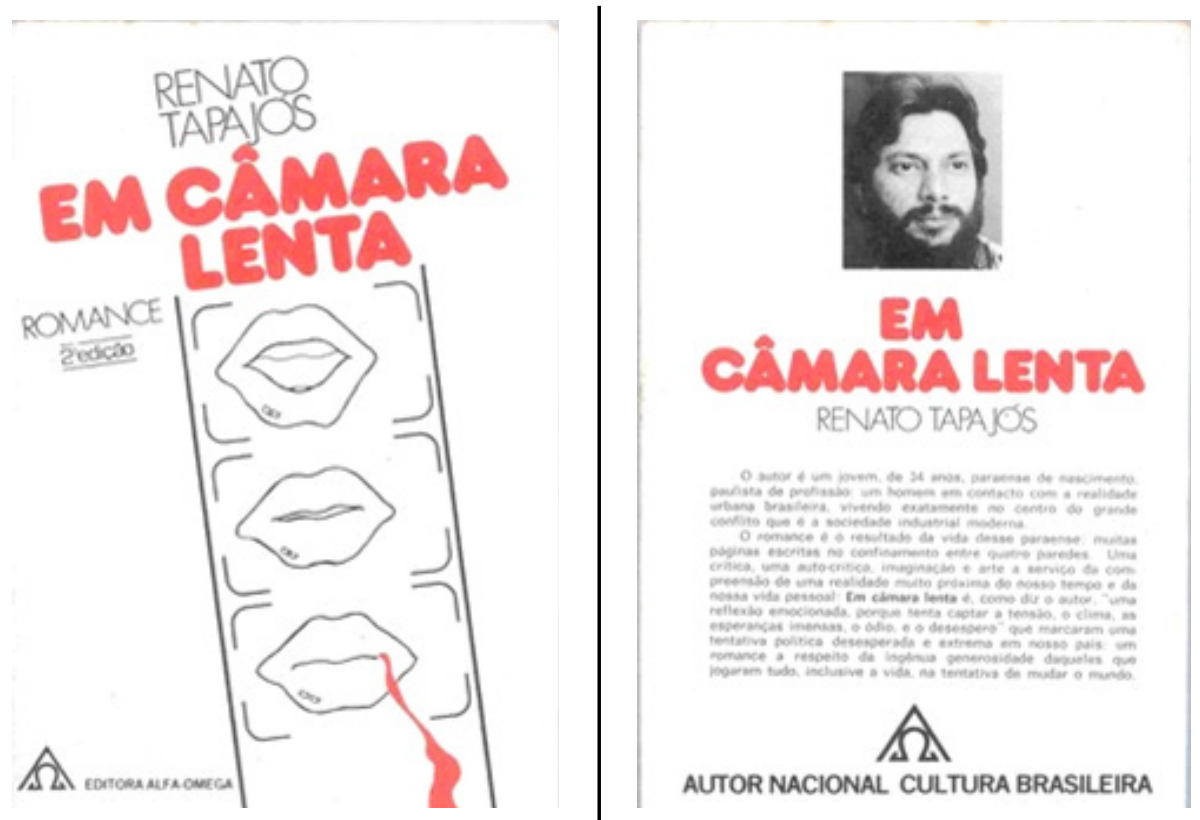

Figuras o1 e 02: Capa e contracapa de Em câmara lenta. Fonte: Acervo particular de Mário A. M. da Silva.

Em câmara lenta, do escritor e documentarista Renato Carvalho Tapajós ${ }^{2}$, teve apenas duas edições e foi publicado em 1977, constituindo-se num momento importante na história literária e política do Brasil no século XX. Antes do sucesso editorial de outro ex-guerrilheiro e exilado, Fernando Gabeira, que publicaria pela

2. Renato Carvalho Tapajós nasceu em Belém do Pará em 1943. A aproximação com a esquerda tem origem familiar, na união que existiu na sua família de comunistas com uma oligarquia decadente, após o intervencionismo de Vargas no estado do Pará. Vem para São Paulo na década de 1960, estudar engenharia na USP. Acaba se interessando por Ciências Sociais, Poesia Concreta e Poesia Práxis e se torna documentarista, autor de Vila da Barca (1967, premiado no Festival de Leipzig), Universidade em Crise (1968), entre outros. Nesse tempo, ingressa na organização maoísta Ala Vermelha. Nos anos 1970, depois de sair da prisão, trabalha na Editora Abril e no programa Globo Repórter, ao lado de Eduardo Coutinho e João Batista de Andrade. Atua na organização sindical de São Bernardo do Campo (1978) que, entre outros fatores, culminaria na criação do Partido dos Trabalhadores (PT), ao qual esteve filiado até 1989. Como escritor, além de Em câmara lenta, é autor de Carapintada, A infância acabou, entre outros, pela editora Ática. Diretor dos filmes Linha de Montagem, Corte Seco, A batalha da Maria Antônia. 
Livro de combate: $O$ caso Em câmara lenta e sua repercussão pública no contexto...

Codecri o famoso O que é isso, companheiro? (GABEIRA, 1978), o livro de Tapajós é o primeiro romance publicado por um autor cujo conteúdo estivesse baseado nas experiências pessoais e tratasse do tema da guerrilha urbana. Com seu romance, Tapajós inicia a revisão do período ditatorial, 13 anos depois do Golpe de 1964 e ainda estando em vigência o regime ditatorial civil-militar.

Inicia, igualmente, o espaço para um novo memorialismo no Brasil, no qual se inseririam posteriormente Antônio Marcello (1978), Gabeira (1982, 1984; primeiras edições em 1978 e 1979, respectivamente), Alfredo Sirkis (1980 e 1981), Reinaldo Guarany Simões (GUARANY, 1978 e 1984), Herbert Daniel (1982) etc., no que diz respeito aos exilados e aos ex-guerrilheiros. A obra desses autores - em maior ou menor grau, encontrando ponto alto no Em câmara lenta - extrapola o nível literário, sem esquecê-lo, e não se resigna apenas à transmissão de experiências. Ao contrário: através da matéria memorialística, gênero de ficção com estatutos de verdade extremamente acentuados, querem promover um julgamento: de si mesmos, de suas experiências, dos seus grupos políticos e/ou geracionais, do Estado ditatorial e da sociedade que o gerou ${ }^{3}$.

\section{EM CÂMARA LENTA E A FANTASMAGORIA DO PASSADO}

O romance de Tapajós é uma construção coletiva, fruto das discussões estabelecidas pelo grupo de guerrilheiros encarcerados no Presídio Tiradentes ${ }^{4}$, em São Paulo, membros da organização de tendência maoísta Ala Vermelha. O autor foi preso em 1969 e solto em 1974, tendo começado a redigir Em câmara lenta em 1973, justamente o momento de maior repressão à oposição armada. O livro é escrito simultaneamente à gestação do documento de autocrítica ${ }^{5}$ dos membros presos

3. Desenvolvi isto com mais detalhes nos capítulos três e quatro de meu livro (SILVA, 2008). Sinteticamente, não é um acaso que estes relatos e romances sejam publicados após o retorno do exílio e saídas das prisões. Eles funcionam como um mecanismo de reinserção social daqueles sujeitos históricos na realidade brasileira do final da década de 1970. Reinserção difícil, especialmente no plano político, em razão do caráter específico assumido pelos movimentos sociais identitários, dos quais os ex-guerrilheiros não conseguem mais ser uma vanguarda política.

4. Sobre o Presídio Tiradentes e as memórias de presos que ficaram encarcerados nele, ver FREIRE, ALMADA, PONCE, 1997.

5. Em entrevista que me concedeu em 25/11/2004, em Campinas, Tapajós afirma que esse documento “[...] é um documento ainda bastante dentro daquele padrão dos documentos comunistas[...]. Isso foi em 73, final de 72, em 73, a gente já tava dizendo praticamente tudo aquilo que até hoje eu acho que tava correto, ou seja, de que nós nos isolamos, que nós desencadeamos o processo de luta armada no momento errado, 
da Ala Vermelha, sendo impregnado pela dimensão da revisão da trajetória e das escolhas assumidas, propondo-se um novo caminho, desde que ele não significasse o abandono da luta contra o regime ditatorial. O autor afirma, na contracapa, que seu livro é:

[...] uma reflexão sobre os acontecimentos políticos que marcaram o país entre $1964 \mathrm{e}$ 1973 e, mais particularmente, entre 1968 e 1973 [...]. É, sobretudo, uma discussão em torno da contradição que se colocou para os militantes, em determinado momento, entre o compromisso moral e as opções políticas que se delineavam. É claro que o romance é também uma denúncia da violência repressiva e da tortura, porque ninguém pode escrever com um mínimo de honestidade sobre política em nosso país, nesse período, sem falar de tortura e de violência policial [...]. No entanto, esse não é o aspecto principal do romance. De certa forma, ele é um balanço e uma autocrítica, um esboço em torno do desmantelamento das organizações de esquerda e da reação dos militantes a respeito desse fato [...]. (TAPAJÓS, 1977).

Desde o título e imagem de capa, Em câmara lenta é montado em linguagem cinematográfica, sendo que a alusão ao cinema, com a qual o editor Fernando Mangarielo $^{6}$, da Alfa-Ômega, batizou os originais, diz respeito aos olhos do personagem central, que aos poucos se fica sabendo ser um narrador guerrilheiro, um homem clandestino, atado às memórias dos mortos e dos presos. $\mathrm{E}$ atado também às reminiscências de Ela, a personagem feminina que assombra as memórias do narrador. $\mathrm{O}$ guerrilheiro narrador de Em câmara lenta é alguém que já não faz mais parte deste mundo, que lhe é estranho, e que insiste em viver até ser morto ou preso, que não duvida do destino trágico, mas também não sabe como se libertar dele.

né? Nós não levamos em conta que a Ditadura ia ser capaz de superar a crise pela qual ela tava passando, que nós nos isolamos da população em função disso daí [...]. E a gente terminava propondo que a alternativa à luta armada era ligar-se às massas, sobretudo ao proletariado organizado nos sindicatos, né? [...] Quando a gente fez a autocrítica a gente reconhece que nós tínhamos caído num desvio de vanguardismo e de esquerdismo, ou seja... Ao sair na frente, com o processo de luta armada, sem estruturar bases significativas junto ao Movimento Social do proletariado e do campesinato [...]” (SILVA, 2008, p. 62).

6. O título que Tapajós queria para os originais era Nem todas as mortes são iguais, segundo a entrevista concedida a mim. Isso porque, segundo o autor, “[...] As mortes daqueles que me são caros, daqueles que eu amo, que fazem parte do meu mundo, por mais ideologia que eu tenha na cabeça, elas não são iguais às mortes dos meus inimigos $[\ldots]$. E o meu personagem vive isso na pele. Porque as pessoas estavam vivendo isso na pele, e eu conheci vários companheiros que foram até o fim, a maior parte deles morreu." (SILVA, 2008, p. 111). 
Livro de combate: $O$ caso Em câmara lenta e sua repercussão pública no contexto...

O LIVRO CENSURADO

Em câmara lenta foi lançado em São Paulo, em maio de $1977^{7}$. O lançamento, segundo o sociólogo Marcelo Ridenti (2000, p. 154), “[...] reuniu uma pequena multidão, convertendo-se num ato político”. Tratava-se do primeiro livro de memórias, um romance, fruto de um militante ativo do período de desenvolvimento e fim das ações armadas e da guerrilha urbana. O livro ficou pouco menos que um mês à venda nas livrarias, e esgotou-se rapidamente sua primeira edição de três mil exemplares. Alguns de seus leitores foram membros do aparelho repressivo do Estado, particularmente da Polícia Civil do Departamento Estadual de Ordem Política e Social (DEOPS) e do II Exército, bem como o então Secretário de Segurança Pública do Estado de São Paulo, o Coronel Antônio Erasmo Dias.

Após as leituras destes últimos, em 27 de julho de 1977, no fim de tarde de uma quarta-feira, no pátio da Editora Abril, onde o autor trabalhava na ocasião, Renato Carvalho Tapajós foi preso por investigadores do DEOPS, chefiados pelo delegado Sérgio Fernando Paranhos Fleury. Configurava-se assim o segundo caso na história editorial e literária brasileira de um autor preso pelo conteúdo de sua obra, no período republicano, ao expôr suas ideias na forma de um livro - o primeiro foi Monteiro Lobato.

O impacto de tal prisão e o espanto causado pelo fato puderam ser sentidos pela mobilização urgente que apareceu nos órgãos de imprensa, tanto da Imprensa Alternativa como de grandes jornais e revistas. Também podem ser medidos pela perplexidade ante uma ação que colocava sob suspeita os planos do General Ernesto Geisel, para uma abertura lenta, gradual e segura, sinalizados, como escreveu Élio Gaspari (GASPARI; HOLLANDA; VENTURA, 1999, p. 13), desde a noite de 12 de janeiro de 1976, quando o General Presidente tomara a decisão de punir com demissão o subordinado de quatro estrelas, General Ednardo d’Ávila Mello, por conta da morte do preso político Manuel Fiel Filho, nas dependências do II Exército.

7. Entre 1975 e 1977 recebeu a recusa de várias editoras, como a Ática e Civilização Brasileira, que consideraram o momento impróprio para lançar uma obra como aquela. A editora que o acolheu, a Alfa-Ômega, havia acabado de lançar a reportagem A ilha, de Fernando Morais e estaria, segundo Marcelo S. Ridenti, "embalada" em publicar material de esquerda, pois fazia sucesso (RIDENTI, 2000, p. 154). De acordo com Fernando Mangarielo, editor e dono da Alfa-Ômega, o que o levou a publicar estas e outras obras foi “[...] o destemor, a identificação com os clamores” da época (SILVA, 2008, p. 142). 
O livro de Tapajós recebeu uma primeira crítica nas páginas da revista Veja, em sua edição da semana de 13 de julho de 1977. Duas semanas antes da prisão do autor, a jornalista Marilena Vianna intitulava suas observações críticas acerca do romance como sendo apenas "Um bom projeto", uma boa ideia que poderia ter contribuído para a revisão crítica do período pós-1964 e que, no entanto, não o fez, sendo impregnada e limitada por uma emoção exacerbada e um unilateralismo analítico que contaminariam a obra. Segundo Vianna (1977, p. 122):

Este romance, entretanto, distingue-se de tudo o que se vem escrevendo sobre o assunto, pelo ineditismo de tratamento, num estilo predominantemente jornalístico, com uma clara tendência ao documental; o enfraquecimento da carga ficcional é, por sua vez, compensado pelo impacto da ação, que, no livro de Renato Tapajós, ocupa lugar privilegiado, centralizando a narrativa; nisto reside sua originalidade [...]. Não conseguindo superar o tom do depoimento pessoal emocionado, o romance não chega a marcar sua presença, de modo significativo, na literatura de revisão do pós-64, por não representar uma tentativa real de interpretação histórica. Ele ousa na distribuição dos papéis principais, na dramatização do assunto; mas pela cumplicidade de sua linguagem, pela forma maniqueísta de equacionar o modo de ser político, a respeito do qual mostra-se profundamente romântico e inocente, fraqueja na crítica e perde-se na passionalidade.

Não foi a mesma opinião de outros leitores da obra de Tapajós, distribuídos no aparato repressivo do Estado, em outros veículos da imprensa ou, posteriormente, na crítica e na análise acadêmica, de quem sua obra mereceu atenção tão logo foi publicada (FRANCO, 1992; FREITAS FILHO; HOLLANDA; GONÇALVES, 1979; MACHADO, 1981). Tratando dos primeiros, a opinião propiciada por Em câmara lenta era de que a obra possuiria um alto teor subversivo. No dia 18 de julho de 1977, cinco dias após a matéria de Veja, o delegado Sérgio Fernando P. Fleury encaminharia à Secretaria de Estado dos Negócios da Segurança Pública um ofício, dizendo ter tomado ciência da publicação da obra do autor, que estaria cumprindo liberdade condicional por ter infringido a Lei de Segurança Nacional (LSN). Ele a teria violado novamente, segundo o delegado, porque sua "obra, cuja análise ora se encaminha, é uma apologia do 'terrorismo da subversão e da guerrilha em todos os seus aspectos' (sic)” (ARQUIVO PÚBLICO DO ESTADO DE SÃO PAULO, 1977a).

Por sua vez, na quinta-feira do dia 21 de julho 1977, a Secretaria de Segurança Pública emitiu documentação confidencial, de difusão restrita a órgãos de 
Livro de combate: $O$ caso Em câmara lenta e sua repercussão pública no contexto...

informação e repressão do Estado, através de sua Seção de Informações, afirmando, na Informação n. ${ }^{\circ}$ 0713/77 - 12109:

Informação No 0713/77 - 12109

A obra "CÂMARA LENTA” de Renato Tapajós: Editora Alfa-Ômega: 1977 - é uma apologia do terrorismo, da subversão e da guerrilha em todos os seus aspectos.

É um "romance" lírico, apaixonado e fanático em que se [ilegível] e se venera o terrorista, o guerrilheiro, e ao mesmo tempo que se execra o policial e o militar.

É uma obra essencialmente feita dentro da dialética marxista, tendo como doutrina e moral a ética comunista. O Comunista não mata, mas liberta! O Comunista não rouba, expropria!

$\mathrm{O}$ assassinato de um policial a tiros de metralhadora é tratado como fato apenas de passagem na narração: a prisão de um terrorista é traduzido num quadro de tortura e de violência que choca a qualquer mortal [...]. (ARQUIVO PÚBLICO DO ESTADO DE SÃO PAULO, 1977b).

Esses argumentos balizaram uma ordem de prisão, ainda que não tivesse sido avalizada pelo procurador da $3^{\text {a }}$ Auditoria Militar, Henrique Vailati Filho - que recebeu a obra, para apreciação, no dia 22 de julho de 1977. A ordem de prisão foi emitida pelo Coronel Antônio Erasmo Dias, seguida de determinação de incomunicabilidade do preso por dez dias. Segundo a matéria publicada no jornal Folha de S. Paulo, de 29 de julho de 1977, na sexta-feira, dois dias seguintes à prisão de Renato Tapajós:

Para o coronel Erasmo Dias, o livro de Renato Tapajós "é uma cartilha subversiva e, depois de ler o romance, cheguei à conclusão de que ele tem mais valia para a subversão do que o "Livro Vermelho" de Mao Tse Tung ou a "Cartilha da Che Guevara” (sic) [...]. Quanto à apreensão da obra o secretário da Segurança Pública afirmou que isso não lhe compete e que os órgãos competentes já foram informados. E acrescentou que Renato Tapajós "é um bom escritor e seu livro foi bem elaborado, mas não tem condição de ficar exposto à venda”. (LIVRO..., 1977, s/p).

Matéria semelhante foi publicada pelo Jornal do Brasil, no mesmo dia, sendo mais incisiva no título, bem encadeado e com clara intenção de demonstrar 
o arbítrio: "Secretário de Segurança de S. Paulo lê romance, acha-o subversivo e prende autor". O jornal destacaria ainda que

o livro foi editado normalmente. Casualmente, o romance caiu nas mãos do Coronel Antônio Erasmo Dias, que encaminhou os informes básicos para apurações e providências do DOPS. O delegado Alcides Singillo, ainda no dia 27, oficiou ao Juiz-

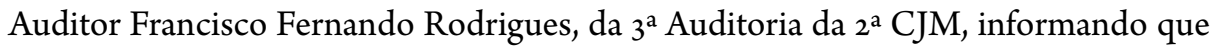
Renato Tapajós se encontrava preso naquele departamento, indiciado em inquérito. (SECRETÁRIO DE SEGURANÇA PÚBLICA..., 1977, s/p, grifo meu).

Três aspectos chamam a atenção nessas reportagens. Primeiro, a ausência da casualidade apontada pelo jornal que, como foi visto linhas antes, na documentação do DEOPS, não existiu. Segundo, a não apreensão da obra, decisão que não teria sido cogitada em detrimento da prisão do autor e cujo expediente era mais comumente praticado pela Censura Federal. Decorrência deste ponto, a prisão do autor, à revelia do indicativo do procurador Vailati Filho, que não a julgara necessária, naquele primeiro momento, para a confecção do inquérito. Bastariam a apreensão e a análise da obra.

Daí surgir a incômoda pergunta, expressa nos jornais dos dias seguintes: Por que Tapajós foi preso?

\section{ManifestaÇões CONTRA A CENSURA}

A partir do dia 30 de julho de 1977, sábado, quase quotidianamente, estendendo-se por todo o mês de agosto, ocorreram, na imprensa, intervenções de intelectuais e associações, sendo entrevistados e publicando notas de protesto contra a prisão. O primeiro jornal a fazer isso foi $O$ Estado de S. Paulo. Na sua edição de 30 de julho de 1977, os professores Dalmo de Abreu Dallari - da Faculdade de Direito da USP e então presidente da Comissão de Justiça e Paz da Arquidiocese de SP - e Paulo Sérgio Pinheiro - sociólogo da UNICAMP e membro do Conselho Orientador da Editora Alfa-Ômega - foram entrevistados acerca da prisão do escritor. Ambos o defenderam: o primeiro caracterizou como inconstitucional sua prisão (bem como a possibilidade de censura à sua obra) e o segundo aprovou o romance, “[...] como uma obra perfeitamente enquadrada no gênero literário. Como leitor, ele destaca, inclusive, a técnica narrativa inovadora de Renato Tapajós que soube tomar 
Livro de combate: $O$ caso Em câmara lenta e sua repercussão pública no contexto...

o tema e desenvolvê-lo numa atmosfera literária surpreendente" (PRISÃO DE FICCIONISTA..., 1977, s/p.).

Para o professor Dallari, seria pouco provável que uma obra de ficção pudesse ser interpretada como meio mais adequado para a realização de propaganda de subversão política. Além disso, a prisão do escritor permaneceria indefensável e arbitrária,

[... "pois o autor tinha residência conhecida, profissão devidamente legalizada e não constituía, portanto, nenhuma ameaça à ordem pública pelo fato de estar livre”. O fato também de ter publicado seu romance com publicidade e através de uma editora cujo proprietário, Fernando Mangarielo, patrocinou o valor literário da obra, demonstra que "o escritor teve boa fé e não justifica prisão preventiva”, segundo o professor Dallari. (PRISÃO DE FICCIONISTA..., 1977, s/p.).

Nos dias que se sucederam, a Associação Paulista de Cineastas (CINEASTAS PROTESTAM..., 1977), a União Brasileira dos Escritores (ESCRITORES DIVULGAM..., 1977) e a Ordem dos Advogados do Brasil, na figura de seu Presidente do Conselho Federal, Raimundo Faoro (ADVOGADO PEDE..., 1977), protestaram contra a prisão. A leitura que o manifesto da UBE faz do romance de Tapajós, certamente em sua defesa, não seria a mesma esperada pelo autor. $\mathrm{O}$ manifesto afirma, a certa altura, que

[...] Contra a tortura estamos todos: está o presidente desta entidade, estão seus associados, está o presidente Geisel, o comandante do II Exército ou o Coronel Erasmo Dias - todos. É evidenciada nesse romance a ingênua generosidade dos jovens que despreparados, isolados de tudo e de todos, sem contato com o povo, os trabalhadores e opinião pública, mas querendo mudar o mundo sem conhecê-lo ou ouvi-lo.[...] Há não muito tempo, as autoridades brasileiras se encarregaram de divulgar, através de todos os meios de publicidade, as confissões e o arrependimento de jovens condenados por atos de terrorismo. Agora, Renato Tapajós apenas coloca em termos de ficção o mesmo libelo contra os que se entregaram à mesquinha agitação (sic) em que o povo era ignorado. (ESCRITORES DIVULGAM..., 1977, s/p.., grifos no original).

Nem mesmo a União Brasileira de Escritores (UBE) entendeu - ou demonstrou querer entender - Em câmara lenta. Tapajós nunca renegou sua experiência, e nem 
seu livro foi feito para isso ou para detratar seus antigos companheiros. Por outro lado, o sociólogo e jurista, Raimundo Faoro, ao comentar a prisão e os fatos que a encerram, resume em poucas e irônicas palavras o quadro de desentendimento e incompreensão - fosse no âmbito do Direito ou no âmbito literário - criado pela prisão de Renato Tapajós:

[...] O presidente do Conselho Federal da OAB, Raimundo Faoro, comentando a prisão de Renato Tapajós, declarou ser "espantoso que havendo Censura Federal, com poderes draconianos, poderes de verificação prévia - segundo uma lei que reputamos inconstitucional mas que está em pleno vigor - a polícia estadual interfira e repute subversivo um livro que à Censura Federal não causou nenhuma impressão negativa. O que se pode concluir é que existe um livro não subversivo para o País, mas especificamente subversivo para São Paulo”. (ADVOGADO PEDE ..., 1977, s/p.).

Os editores de Tapajós, o casal Fernando e Claudete Mangarielo, foram intimados, no dia 03 de agosto de 1977, a depor sobre o livro que publicaram e que, até aquela data, ainda não havia sido censurado e já esgotara sua primeira edição. Nessa ocasião, o então deputado do MDB, Alberto Goldman, e a Academia Brasileira de Letras, representada por seu presidente Austregésilo de Athayde, manifestaram seu repúdio à prisão de Tapajós, que permanecia incomunicável e era defendido pelo advogado Aldo Lins e Silva - de quem os órgãos de informação diriam se tratar de notório defensor de presos políticos e elemento de esquerda. A Câmara Brasileira do Livro, através de Mário Fittipaldi, também manifestou seu protesto, naqueles dias, assim como o Sindicato dos Escritores de São Paulo, numa pressão constante, entre os dias o2 e o5 de agosto de 1977.

No depoimento dos Mangarielo, no dia o3, o editor teria afirmado, segundo o jornal Folha de S. Paulo, que “[...] os critérios empregados para a edição do livro foram uma análise de conteúdo sobre o valor literário da obra e a realização de uma pesquisa mercadológica, 'que resultou satisfatória, visto que os livros que tratam de ficção política provocam grande receptividade junto ao público'” (EDITOR DE TAPAJÓS ..., 1977, s/p.).

Duas semanas mais tarde, no dia 17 de agosto de 1977, o comando do II Exército emitiria uma opinião diferente acerca do livro, em seus mais diferentes aspectos (desde a composição física até as intenções de seu conteúdo). Em seu Relatório de Análise, de número 201, a certa altura, o documento afirma que o livro foi produzido 
Livro de combate: $O$ caso Em câmara lenta e sua repercussão pública no contexto...

com "Capa e interior elaborados em papel de baixo preço, objetivando o barateamento de produção, escrito com letras graúdas e linguagem fácil para atingir diversificados níveis de leitores" (ARQUIVO PÚBLICO DO ESTADO DE SÃO PAULO, 1977c, s/p.). Voltar-se-á a esse relatório mais adiante.

A incomunicabilidade de Tapajós - que até então não tinha o direito de avistar-se com advogados ou receber visitas, ler jornais, livros etc. - terminou no dia o6 de agosto de 1977. Ainda assim, permaneceria com prisão preventiva decretada por mais 30 dias, período no qual continuaria a prestar depoimentos. Nesse ínterim, entre o6 e o9 de agosto, foi lançado em São Paulo manifesto com quase 800 assinaturas de escritores, jornalistas, artistas plásticos etc. A notícia e o manifesto foram divulgados pelos jornais Folha de S. Paulo e O Estado de S. Paulo no mesmo dia (o9 de agosto de 1977): no primeiro mereceram apenas uma pequena nota de poucas linhas; e, no segundo, publicou-se o texto como um todo, embora sem as assinaturas, como pode ser visto a seguir:

Nós abaixo-assinados, escritores, cineastas, jornalistas, atores, teatrólogos e artistas plásticos, profissionais cuja atividade depende fundamentalmente da liberdade de pensamento e de expressão, protestamos publicamente contra a prisão, em São Paulo, do escritor Renato Tapajós. Achamos impertinente ao caso a discussão do passado do escritor: trata-se de fatos julgados pelo Judiciário, que não podem ser invocados para justificar a arbitrariedade cometida agora. Pela primeira vez no Brasil, um autor é preso porque o conteúdo de seu romance, editado e vendido legalmente, foi considerado subversivo pela autoridade policial. Essa violência fere frontalmente a liberdade de manifestação de pensamento, consagrada nos "Direitos e Garantias Individuais" da Constituição e, pelo precedente que estabelece, constitui para todos nós uma ameaça intolerável. Agosto de 1977. (PRISÃO DE TAPAJÓS..., 1977, s/p.).

Somente quase um mês depois da prisão de seu autor e três meses depois de seu lançamento, Em câmara lenta foi censurado em nível nacional pelo então Ministro da Justiça, Armando Falcão. O assunto foi noticiado apenas pela Folha de S. Paulo, de 13 de agosto de 1977:

BRASÍLIA (Sucursal) - O ministro da Justiça, Armando Falcão, assinou despacho ontem, proibindo a publicação e circulação em todo o território nacional do livro "Em Câmara Lenta”, da autoria de Renato Tapajós, escritor e jornalista preso recentemente 
por determinação do secretário de Segurança Pública do Estado de São Paulo, coronel Erasmo Dias. Por outro lado, foi determinado à Polícia Federal a apreensão de todos os exemplares expostos à venda. A proibição de "Em Câmara Lenta", publicado pela Editora Alfa-Ômega de São Paulo, foi baseada no artigo 54 do decreto lei 898, de 29 de setembro de 1969 - Lei de Segurança Nacional. O despacho do ministro Armando Falcão foi encaminhado à Procuradoria Geral junto à Justiça Militar. (FALCÃO PROÍBE..., 1977, s/p.).

Numa ação concertada, apreende-se o livro de Tapajós, censura-se e expede-se o recolhimento, ao mesmo tempo em que se pede a sua prisão preventiva, por crime de incitação à subversão, baseado na Lei de Segurança Nacional. A notícia deste fato é divulgada pelo jornal O Estado de S. Paulo, de 18 de agosto de 1977.

O delegado Alcides Singillo, da Divisão de Ordem Social do Deops de São Paulo encaminhou ontem $2^{\text {a }}$ Circunscrição Judiciária Militar o inquérito em que é indiciado o jornalista Renato Carvalho Tapajós, por subversão e solicitou a decretação de prisão preventiva. Singillo, que presidiu o inquérito, fez uma demorada análise do livro "Em Câmara Lenta" e da atuação do acusado dentro da ala vermelha do Partido Comunista do Brasil, retratada integralmente, segundo o delegado, no livro. [...]. No inquérito realizado pelo Deops e encaminhado à Justiça Militar, o delegado Singillo afirma que o livro de Tapajós não apresenta uma ficção, "mas sim uma apologia da subversão, do terrorismo e da guerrilha rural e urbana”. O delegado assegura que, de acordo com confissão do autor, os personagens principais são o próprio Renato Tapajós, sua cunhada Aurora Furtado, ex-militante da Aliança Libertadora Nacional, morta na prisão, e seu amante José Arantes. (PEDIDA A PRISÃO..., 1977, s/p.).

A "demorada análise do livro" de que fala a reportagem é o "Relatório de Análise no 201 ", datado de 17 de agosto de 1977, no qual a autoria do remetente e a do destinatário, no II Exército, são indicadas por meio de códigos. Trata-se de documento de nove páginas, que faz um resumo, inicialmente, das atividades de Tapajós na Ala Vermelha, que o condenaram à prisão entre 1969 e 1974. Após isso, o documento faz uma breve apresentação da Editora Alfa-Ômega e de seus membros à época da publicação de Em câmara lenta (editores, conselho orientador, revisores etc.). Na sequência, em seu quinto item, procede-se a uma "Análise Circunstancial da Obra", que se ocupa em provar que o livro de Tapajós, da maneira física como foi editado 
Livro de combate: $O$ caso Em câmara lenta e sua repercussão pública no contexto...

- papel, tipografia etc.) -, passando pela capa, até o seu conteúdo, é instrumento para incitação à subversão, concluindo pela culpa de Tapajós. E ressalta ainda o precedente perigoso que publicações como a obra Em câmara lenta abririam, naquilo que parte da crítica literária chamou de Moderno Memorialismo Brasileiro. Como conclui Singillo, ao final de seu relatório:

Outro aspecto a ser abordado é que o livro "EM CÂMARA LENTA" seja nada menos que o embrião de uma nova modalidade de ataques e calúnias aos Governos, disfarçada por uma casca literária, o que confirma a publicação pela mesma editora do livro "UMA VIDA EM SEIS TEMPOS (MEMÓRIAS)", de autoria de um ex-membro do Comitê Central do PCB, o qual já está sendo objeto de análise por esta Seção, onde se percebe um afinamento acadêmico com a técnica de terrível eficácia, utilizada por PAUL JOSEPH GOEBBELS, Ministro da Propaganda da Alemanha Nazista, baseada na premissa "Mintam, mintam que sempre alguma coisa ficará". (ARQUIVO PÚBLICO DO ESTADO DE SÃO PAULO, 1977d, s/p.).

O advogado de Renato Tapajós e da Alfa-Ômega, Aldo Lins e Silva, segundo noticiou a Folha de S. Paulo no dia seguinte (ADVOGADO REQUER..., 1977, s/p), solicitou, para contrapor à análise literária elaborada pelo delegado do DEOPS, um parecer técnico do professor de Teoria Literária e Literatura Comparada da USP, Antônio Candido de Mello e Souza, que aceitou o pedido e procedeu à análise minuciosa dos aspectos literários e intencionais de Em câmara lenta, bem como de seu autor. $\mathrm{O}$ documento final do professor Candido foi lido durante a defesa de Tapajós e está datado de 12 de fevereiro de 1978 . Ele se encontra reproduzido na íntegra no Anexo de Documentos de meu livro (SILVA, 2008).

\section{A EXIGÊNCIA DA LIBERDADE}

Renato Tapajós foi solto em 23 de agosto de 1977, às $17 \mathrm{~h} 30 \mathrm{~min}$, do Presídio do Hipódromo de São Paulo, para onde havia sido transferido dias antes. O mandado de soltura foi solicitado pelo procurador Henrique Vailati Filho - que pediria a sua condenação um mês depois, em 30 de setembro de 1977. A notícia da liberdade de Tapajós foi dada pelos jornais Folha de S. Paulo (PROCURADOR QUER..., 1977; TAPAJÓS SOLTO..., 1977) e O Estado de S. Paulo (LIBERTADO RENATO TAPAJÓS, 1977). Ao fim da reportagem deste último jornal, afirma-se que havia 
um grande temor entre os policiais de plantão da delegacia, uma vez que "nos vinte dias que permaneceu no DOPS, Renato Tapajós foi constantemente vigiado por carcereiros, que informaram ter recebido instruções para evitar a qualquer custo 'um possível suicídio' ”. (LIBERTADO RENATO TAPAJÓS, 1977, s/p.).

Certamente esse temor era provocado pela (até então tida e reafirmada como suicídio pelos órgãos oficiais) morte do jornalista Vladmir Herzog, nas mesmas dependências do DEOPS, dois anos antes, onde esteve preso Tapajós por um mês.

Esse temor dos policiais é diferente daquele expresso pelo grande volume de cartas que começaram a chegar ao Gabinete do Secretário de Segurança Pública de São Paulo, Coronel Erasmo Dias. A procedência, em geral, era de membros ou simpatizantes de diversas seções da Anistia Internacional espalhados pelo mundo. As cartas foram remetidas de países de quatro continentes (Dinamarca, Finlândia, Alemanha, Hong Kong, Holanda, Canadá, Suécia, Estados Unidos, Austrália, Venezuela, Suíça etc.). O assunto: pedido de soltura imediata de Renato Tapajós, bem como temor por sua vida nas dependências do DEOPS.

O conteúdo básico de todas as cartas escritas em português, pelos estrangeiros, com erros de ortografia, era (ARQUIVO PÚBLICO DO ESTADO DE SÃO PAULO, 1977e):

Coronel Antônio Erasuno Dias (sic)

Secretaria de Segurança Pública

Cabinete do Secretario (sic)

Av. Brigadeiro Tobias, 527 - 10 andar.

São Paulo-SP, Brasilien. (sic)

Exmo. Sr. Secretario de Segurança Publica!

No dia 27 de julho, 1977, o escritor, cineastra (sic) e jornalista RENATO TAPAJÓS foi preso pelo DOPS en (sic) São Paulo.

A vida do Sr. Renato Tapajós corre sério risco já que ele se encontra incomunicado (sic) e talvez sofra torturas.

Peço a V. Exia. (sic) que garanta ao Sr. Renato Tapajós um tratamento de acordo com os direitos humanos bem como sua soltura imediata.

Saudações,

Assinatura. 
Livro de combate: $O$ caso Em câmara lenta e sua repercussão pública no contexto...

Sobre a circulação mundial do caso Em câmara lenta, Tapajós afirma:

Então a primeira edição esgotou rapidamente, aí veio a Censura, proibiu o livro e tal... Em 79, já na época da Anistia, quando foi suspensa a Censura e o livro foi lançado, a maior parte das pessoas que... A maior parte do público que tinha prá ler o livro, já tinha lido. Em cópia xérox (risos). Eu fiquei sabendo de gente que leu o livro em cópia xérox em Moçambique, em Angola, na Argélia, no... Na Europa, várias pessoas, entendeu? Quer dizer, eu não sei quantas cópias xérox fizeram, mas esse livro circulou muito mais em cópias xérox do que em cópias vendidas pela editora, né? (SILVA, 2004, s.p.).

O General do Exército e Ministro do Superior Tribunal Militar, Augusto Fragoso, comunicou, em o2 de setembro de 1977, o recebimento de 89 cartas provenientes do exterior, apelando pela soltura de Tapajós e temendo por sua vida (APELOS POR..., 1977).

Após a liberdade concedida ao escritor e as pressões sofridas pelos órgãos de Segurança Pública, as notícias e o interesse pelo caso Tapajós decresceram nos jornais. As duas últimas grandes matérias sobre o assunto foram fornecidas pelo Jornal do Brasil (PROCURADOR DENUNCIA..., 1977) e pela Folha de S. Paulo (APRESENTADA A DENÚNCIA..., 1977), espaçadas em quase um mês. No primeiro caso, no dia 30 de setembro de 1977, ambos os periódicos publicaram que o Procurador da Justiça Militar, Henrique Vailati Filho, finalmente havia apresentado sua denúncia ao Ministério Público contra o escritor e seu livro. A acusação se basearia no crime de incitação à subversão, previsto no artigo 47 da Lei de Segurança Nacional e que condenaria o acusado, se provada a culpa, a um período de 02 a 05 anos de prisão. O livro de Tapajós, na visão do procurador, seria altamente condenatório, pelo fato de Tapajós ser:

[...] homem de invulgar cultura e talento imenso, faz uma obra literariamente preciosa se converter em tribuna para o incitamento à guerra revolucionária e apologia do terrorismo [...]. Absurdo é de se dizer que uma obra, ainda altamente artística, não pode ser o veículo da subversão. O importante é a análise de seu conteúdo, e a finalidade que lhe dá o autor e que emerge clara [...] há em toda narrativa, que flui harmoniosa e absorvente, um tom patético, algo de profundamente humano como imã psicológico a captar a simpatia do desavisado para a ação dos guerrilheiros que saltam em cena como quixotes esquálidos e se convertem, nas pinceladas de tonalidade cada vez 
mais intensa, em imitáveis bayards, brandindo o gládio com o destemor dos justos. (PROCURADOR DENUNCIA..., 1977, s/p.).

A essa análise de conteúdo, que em muito se assemelha à do delegado Singillo do DEOPS ou do relatório informativo do delegado Fleury à Secretaria de Segurança Pública, Tapajós responderia em audiência no dia 25 de outubro de 1977, negando e refutando as acusações perante o Conselho Permanente de Justiça da Aeronáutica, na $3^{\text {a }}$ Auditoria da $2^{\text {a }}$ Circunscrição Judiciária Militar (PROCURADOR DENUNCIA..., 1977). Seus argumentos são, basicamente, de que seu livro é uma crítica à guerrilha e à luta armada como formas de atuação política no País, destacando aspectos do romance; em especial, a trajetória da personagem principal. Suas argumentações, em nível literário, seriam reforçadas pelo parecer técnico de Antônio Candido de Mello e Souza - aqui reproduzidos nas Figuras de 2 a 6 - e junto com a atuação de Aldo Lins e Silva culminariam no arquivamento do processo.
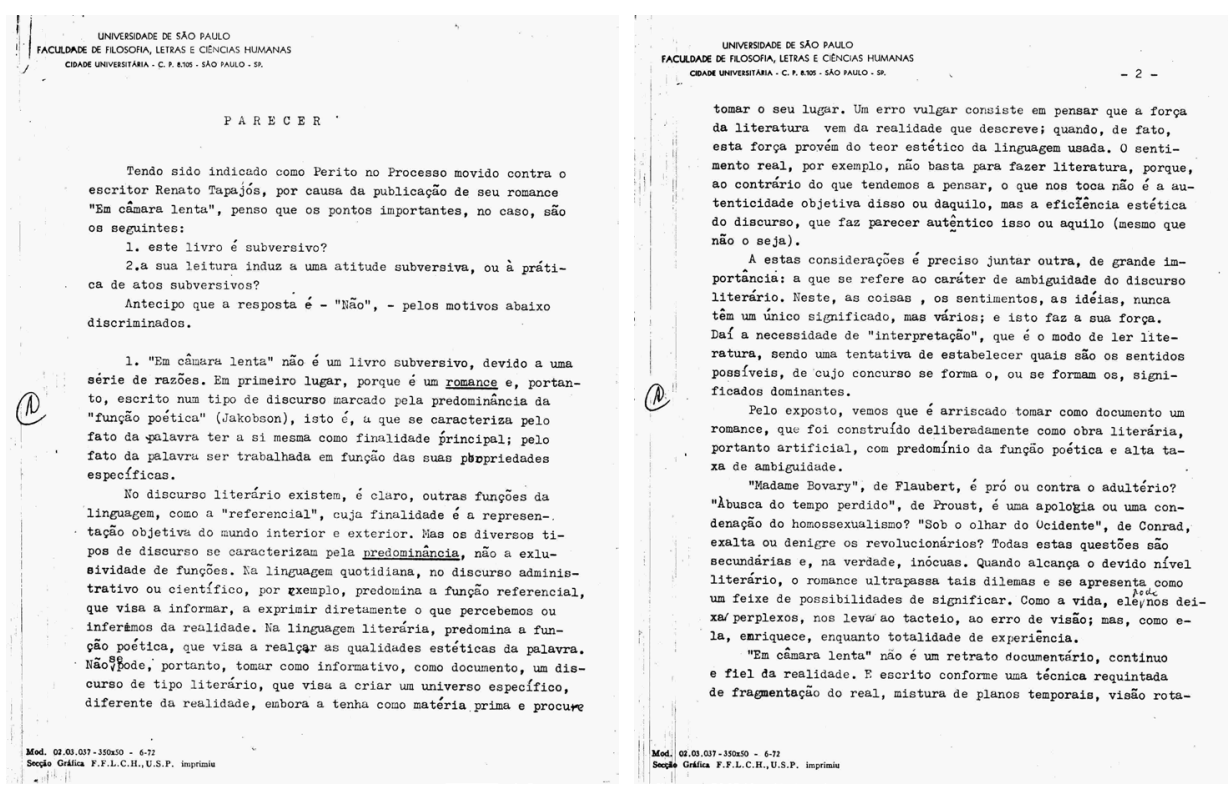
Livro de combate: $O$ caso Em câmara lenta e sua repercussão pública no contexto...
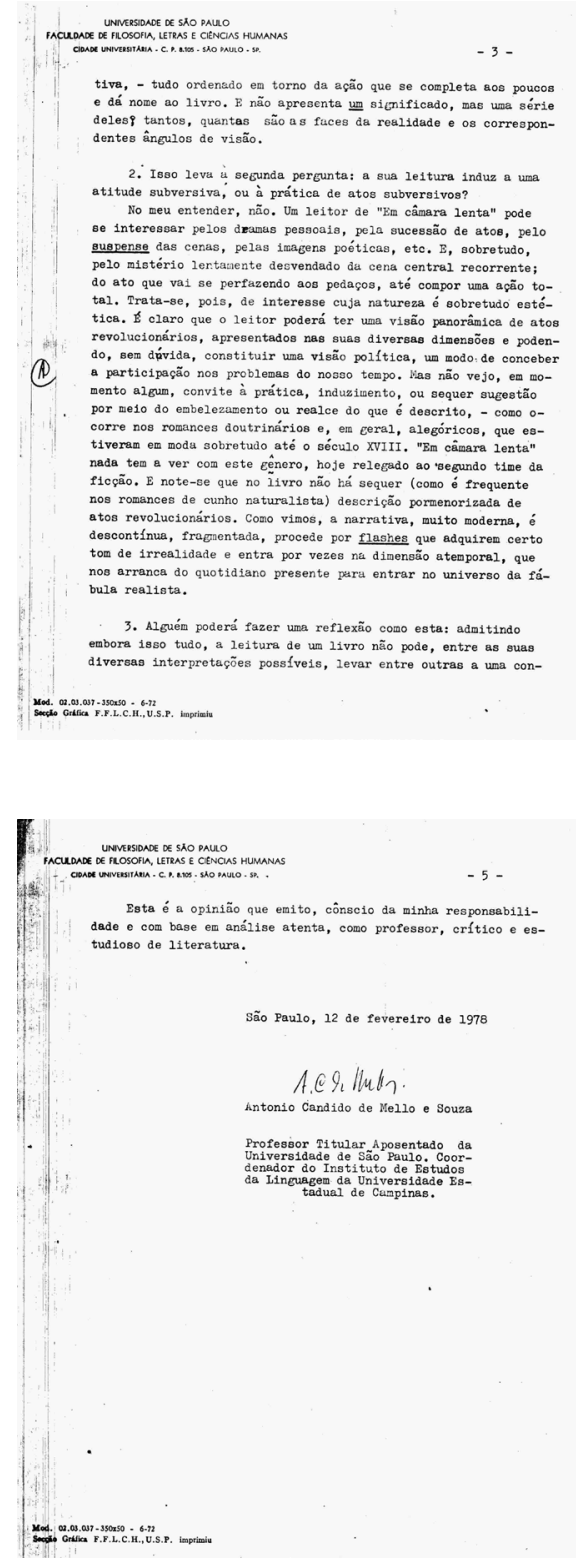

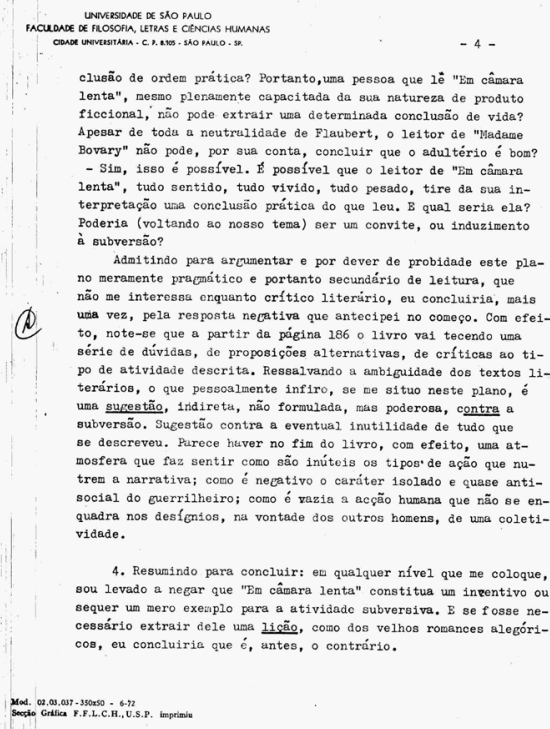

(1) unia vez, pele resposta necativa que antecipei no começo. Com ofe1to, note-se que a partir da página 186 o livro vai tecendo una série de duvldas, de proposiçoes alternativas, de críticas ao tipo do atividade descrita. Resoalvando a anbieuidade dos textos literários, o que pessoalmente infiro, se we situo neste plano, e una sucestäo, 1ndireta, não formulada, mas poderose, contra a se descrever. Puroce hutar a eventual inutilidade de tuado que mosfera auc faz entir tran a narrativa; comó nemativo o arot por de ça que nusocial do cuerristeiro; quadra nos desífnios, na vontade dos outros homens, de una ce env1dede.

4. Resurindo para concluir: en qualguer nível que ne cologue, sou levado a negar que "En câmara lenta" constitua um inrentivo ou sequer um mero exesiplo para a atividade subversiva, $E$ se fosse necessário extrair dele una liseão, cono dos velhos romances alegóricos, eu concluiria que é, antes, o contrário.

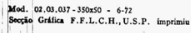

Figuras 03, 04, 05, 06 e 07: As páginas originais do parecer de Antonio Candido, utilizado pela defesa de Renato Tapajós. Fonte: Arquivo pessoal de Renato Carvalho Tapajós. Ver: Silva (2008, p. 235-240).

Em 1978, o Jornal da Tarde, na edição de 19 de janeiro de 1978, retomaria o caso Tapajós (NA ESTRÉIA..., 1978, s/p). Segundo o jornal, o escritor entraria com uma 
ação cautelar na Justiça para tentar a liberação de seu livro. Afirma-se, dentre outras considerações positivas sobre o autor e o romance que

[...] Atualmente, Renato Tapajós está escrevendo um novo romance que aborda a vida de operários da região de São Bernardo do Campo. O enredo gira em torno de um clima passional, mas pouco a pouco se desliga desse acontecimento para abordar as vidas das pessoas envolvidas no crime.

O romance não foi publicado e não se tem notícia de que tenha sido finalizado. As notícias sobre o processo Tapajós correram esparsas a partir daí, mas não menos interessantes. Em o2 de março de 1978, a Folha de S. Paulo divulga que a defesa do autor, conduzida por Aldo Lins e Silva, estava concluída (DEFESA DE TAPAJÓS..., 1978), o que, como publicou o mesmo jornal em 25 de abril de 1978, permitiu a instauração do julgamento, que ocorreria às $14 \mathrm{~h}$ do mesmo dia, na $2^{\mathrm{a}}$ Auditoria Militar (ESCRITOR É JULGADO..., 1978).

$\mathrm{O}$ que ocorreu naquela ocasião foi a revelação de um processo sem fundamentos jurídicos claros, embora a acusação conduzida por Henrique Vailati Filho quisesse provar o contrário, como se vê, na ocasião em que Tapajós foi absolvido:

O julgamento começou às 14 horas com a leitura das principais peças do processo, seguindo-se a acusação pelo procurador da Justiça Militar, Henrique Vaillati Filho, que considerou o livro de Tapajós como "incitamento à guerra revolucionária”. $\mathrm{O}$ advogado de defesa, Aldo Lins e Silva, considerou a denúncia inepta e pediu para que se deixasse o livro para os entendidos, fazendo em seguida a juntada aos autos de parecer do professor Antônio Cândido de Mello e Souza, da USP, que externou ponto de vista segundo o qual a obra de Tapajós não era de cunho subversivo. $\mathrm{O}$ advogado falou ainda do manifesto da União Brasileira dos Escritores em favor de Tapajós, afirmando em seguida que o livro não chegou a ser vendido pelo que estranhava que a denúncia não sopesasse possível responsabilidade do editor e dos componentes do Conselho Consultivo da Editora. Respondendo, o representante do Ministério Público Militar disse que não incluíra o editor e seus companheiros na denúncia porque eles só analisaram a obra por suas características de venda, sendo pois o autor o único responsável pelos conceitos emitidos. [...] O procurador disse ainda que na condição de professor de Literatura há 33 anos, tem conhecimento mais do que suficiente para a crítica do livro.[...] Terminou dizendo 
Livro de combate: $O$ caso Em câmara lenta e sua repercussão pública no contexto...

que, ao contrário do que afirma a defesa, a edição do livro está totalmente esgotada. O Conselho Permanente de Justiça reuniu-se em sessão secreta, proclamando em seguida o resultado do julgamento absolvendo Renato Carvalho Tapajós. (CONSELHO ABSOLVE..., 1978, s/p.)

As matérias de 26 de abril da Folha da Tarde (FOI ABSOLVIDO..., 1978) e da Folha de S. Paulo (ABSOLVIDO AUTOR..., 1978, s/p) são unânimes em festejar a absolvição em primeira instância do escritor. Este último jornal, nessa mesma matéria, transcreveu momentos do julgamento que parecem ser inusitados, como descritos a seguir:

Ao absolver o acusado, o Conselho rejeitou, também por unanimidade, a proposição da defesa para que aquele tribunal militar se considerasse incompetente para julgar a matéria. Em decisão lida pelo presidente do Conselho, major Cláudio José Vieira da Silva, o tribunal considerou-se competente e, em conseqüência proferiu a decisão, absolvendo o acusado. A seguir, o presidente do Conselho desceu ao plenário e cumprimentou Renato Tapajós. [...] "Assim, temos de julgar conforme as condições de cada época - argumentou [Henrique Vaillati Filho] - mesmo que amanhã essas condições mudem. Tiradentes, então condenado, é hoje herói nacional. E se Hitler tivesse vencido a II Guerra Mundial, certamente ele seria hoje o herói nacional da Alemanha”. [... ] Henrique Vailatti Filho, no entanto, reconheceu "Em Câmara Lenta" como "uma obra de arte, inegavelmente, e devo admitir que gostei muito", mas afirmou nela ter enxergado incitação e apologia a atos subversivos.

Os promotores militares afirmaram que, forçados pelo dispositivo da Lei de Segurança Nacional, eram obrigados a recorrer da decisão da Auditoria Militar junto ao Supremo Tribunal Militar - procedimento exigido em casos de absolvição. Também nessa instância, Tapajós foi absolvido, concluindo assim um dos casos mais extraordinários de arbitrariedade, abuso de poder e, até mesmo, disputas de leituras e visões de mundo a partir de uma mesma obra, conhecidos nas histórias política e literária brasileiras contemporâneas. É bastante ilustrativo, nesse aspecto, um trecho da leitura final do Ministro Lima Torres, relator do processo, pela qual encaminhava a absolvição, noticiada em $O$ Estado de $S$. Paulo (STM ABSOLVE..., 1978) e na Folha de S. Paulo (STM NEGA..., 1978): 
“Se, de um lado, se menciona a ação repressiva, às vezes dita violenta, outras há em que não é menor a violência e a insensibilidade dos indigitados defensores da nova ordem".

Em 1979, o jornal alternativo $O$ Movimento, em sua $195^{\mathrm{a}}$ edição, anunciaria a liberação do livro de Tapajós, configurando-se como

o último ato do ex-ministro da Justiça, Armando Falcão, publicado no Diário Oficial do dia 17, foi liberar à circulação o romance "Em Câmara Lenta”, de Renato Carvalho Tapajós. Por causa dele, há dois anos atrás, o autor foi preso e processado pela Justiça Militar, sendo posteriormente absolvido. O livro foi recolhido das livrarias e, durante muito tempo, teve como único crítico e leitor o então Secretário da Segurança do Estado, coronel Erasmo Dias, que se referiu várias vezes a ele como sendo "obra notoriamente subversiva”. (A GUERRILHA..., 1979, p. 21).

Após isso, já em 23 de maio de 1979, Em câmara lenta apareceria na $560^{a}$ edição da Revista Veja daquela semana, na Seção “Os Mais Vendidos”, como o nono colocado entre os dez mais, na categoria ficção. Ainda receberia uma crítica de Fernando Gabeira para o jornal de literatura Leia Livros ${ }^{8}$, finalizando sua recepção crítica no período abrangido por este artigo. O livro não possuiu ediçõos posteriores.

\section{REFERÊNCIAS}

DANIEL, Herbert. Passagem para o próximo sonho: um possível romance autocrítico. Rio de Janeiro: Codecri, 1982.

FOUCAULT, Michel. O que é um autor? Tradução de António F. Cascais e Eduardo Cordeiro. Lisboa: Vega, 1992.

8. "No que diz respeito à temática de luta armada e repressão, pelo menos três importantes romances surgiram no Brasil nesses últimos dez anos. Pela ordem de aparição: Em Câmara Lenta, de Renato Tapajós, Nas Profundezas do Inferno, de Artur J. Poerner e Cabeça de Negro, de Paulo Francis. Em Câmara Lenta, de Tapajós, foi proibido e talvez tenha sido o único romance na história recente que valeu a prisão ao seu autor. Em Câmara Lenta confirma a proximidade que Tapajós tem com o cinema, a mesma proximidade que o levou a preparar documentários sobre o movimento operário. A técnica do cinema estava presente no romance psicológico contando as angústias dos guerrilheiros em processo de destruição. $O$ passo seguinte foi a documentação cinematográfica do movimento operário, autocrítica social e na prática daquele período elitista. Tapajós capta o drama do guerrilheiro e joga para toda a sociedade um outro drama: como julgá-los? É verdade que estavam errados mas não há dúvida de que toda a generosidade e disponibilidade de uma geração foi jogada ali e reprimida a bala e a pau-de-arara. [...]" (GABEIRA, 1980, p. 20). 
Livro de combate: $O$ caso Em câmara lenta e sua repercussão pública no contexto...

FRANCO, Renato B. Fiç̧ão e política no Brasil: os anos 70. 1992. Dissertação (Mestrado em Teoria Literária)- Instituto de Estudos da Linguagem, Universidade Estadual de Campinas, Campinas, 1992.

FREIRE, Alípio; ALMADA, Isaías; PONCE, J. A. de (Org.). Tiradentes, um presídio da ditadura: memórias de presos políticos. São Paulo: Scipione Cultural, 1997.

FREITAS FILHO, Armando F.; HOLLANDA, Heloísa B. de; GONÇALVES, Marcos A. Anos 7o: Literatura. Rio de Janeiro: Edições Europa, 1979.

GABEIRA, Fernando. As memórias e a literatura política nos anos 70 . $\mathrm{O}$ romance na política: um balanço. Leia Livros, n. 20, p. 20, 15 dez.-14 fev. 1980. . O que é isso, companheiro? 32. ed. Rio de Janeiro: Nova Fronteira, [1978]1982. . O crepúsculo do macho. 23. ed. Rio de Janeiro: Nova Fronteira, 1984.

GASPARI, Élio; HOLLANDA, Heloísa B. de; VENTURA, Zuenir. Cultura em trânsito. Rio de Janeiro: Aeroplano, 1999.

GUARANY, Reinaldo. Os fornos quentes. São Paulo: Alfa-Ômega, 1978. . A fuga. São Paulo: Brasiliense, 1984.

MACHADO, Janete Aparecida Gaspar. Constantes ficcionais em romances dos anos 70, Florianópolis: Ed. da UFSC, 1981.

MARCELLO, Antônio. Ensaio geral: ficção política. São Paulo: Alfa-Omega, 1978.

PELLEGRINI, Tânia. Gavetas vazias: ficção e política nos anos 70, Campinas: Mercado de Letras; São Carlos: Ed. da UFScar, 1996.

RIDENTI, Marcelo S. Em busca do povo brasileiro. Rio de Janeiro: Record, 2000.

SILVA, Mário Augusto Medeiros da. Entrevista com Renato Tapajós. Campinas, 25 de novembro de 2004.

. Os escritores da guerrilha urbana: literatura de testemunho, ambivalência e transição política (1977-1984). São Paulo: Annablume, 2008.

SIRKIS, Alfredo. Os carbonários: memórias da guerrilha perdida. 4. ed. São Paulo: Global, 1980. . Roleta chilena. 2. ed. Rio de Janeiro: Record, 1981.

TAPAJÓS, Renato. Em câmara lenta, São Paulo: Alfa-Ômega, 1977.

VIANNA, Marilena. Um bom projeto. Veja, São Paulo: Abril, n. 462, p. 122, 13 jul. 1977.

\section{ARtigos de PERIódicos}

ABSOLVIDO AUTOR DE EM CÂMARA LENTA. Folha de S. Paulo, 26 abril de 1978. ADVOGADO PEDE ACESSO AO PRESO. Folha de S. Paulo, o2 de agosto de 1977. ADVOGADO REQUER A SOLTURA DE TAPAJÓS. Folha de S. Paulo, 19 de agosto de 1977.

A GUERRILHA LIBERADA EM CÂMARA LENTA. O Movimento, n. ${ }^{\circ}$ 195, 26/o3/1979 01/04/1979, p. 21.

APELOS POR TAPAJÓS. Folha de S. Paulo, o3 de setembro de 1977.

APRESENTADA A DENÚNCIA CONTRA TAPAJÓS. Folha de S. Paulo, 30 de setembro de 1977. ARQUIVO PÚBLICO DO ESTADO DE SÃO PAULO. Ofício nº. 818/77. Documento 40-Z-11128. Acervo DEOPS. São Paulo, 1977a. (microfilme). 
ARQUIVO PÚBLICO DO ESTADO DE SÃO PAULO. Informação n. $.^{\circ} 0713 / 77$ - 12109. Documento 21-Z-14-3249. Acervo DEOPS, 1977b. (microfilme).

ARQUIVO PÚBLICO DO ESTADO DE SÃO PAULO. Documento encontrado através das

Referências de Aldo Lins e Silva (5o-Z-941891) e Fernando Mangarielo (5o-Z-9-41894 - 1977 e 50-Z-9-41895 - 1977. Acervo DEOPS, 1977c.

ARQUIVO PÚBLICO DO ESTADO DE SÃO PAULO. Relatório de Análise n. 201 - Conclusão. Documento 50-Z-41891 (Pasta). Acervo DEOPS, $1977 \mathrm{~d}$.

ARQUIVO PÚBLICO DO ESTADO DE SÃO PAULO. Documentos 30-B-38-1002 (microfilme) e 30-B-38-1001 (microfilme) através da referência Renato Tapajós. Acervo DEOPS, 1977 e.

CINEASTAS PROTESTAM CONTRA A PRISÃO DE RENATO TAPAJÓS. Folha de S. Paulo, 31 de julho de 1977.

CONSELHO ABSOLVE TAPAJÓS. O Estado de S. Paulo, 26 de abril de 1978.

DEFESA DE TAPAJÓS ESTÁ CONCLUÍDA. Folha de S. Paulo, o2 de março de 1978.

EDITOR DE TAPAJÓS PRESTA DEPOIMENTO NO DEOPS PAULISTA. Folha de S. Paulo, 04 de agosto de 1977.

ESCRITORES DIVULGAM PROTESTO CONTRA A PRISÃO DE TAPAJÓS. O Estado de S. Paulo, O2 de agosto de 1977.

ESCRITOR É JULGADO HOJE EM SÃO PAULO. Folha de S. Paulo, 25 de abril de 1978.

FALCÃO PROÍBE LIVRO DE TAPAJÓS. Folha de S. Paulo, 13 de agosto de 1977.

FOI ABSOLVIDO RENATO TAPAJÓS. Folha da Tarde, 26 de abril de 1978.

LIBERTADO RENATO TAPAJÓS. O Estado de S. Paulo, 24 de agosto de 1977.

LIVRO PUBLICADO PROVOCA A PRISÃO DO ESCRITOR. Folha de S. Paulo, 29 de julho de 1977.

NA ESTRÉIA, CENSURA E VIOLÊNCIA CONTRA TAPAJÓS. E O SUCESSO. Jornal da Tarde, 19 de janeiro de 1978.

PEDIDA A PRISÃO DE RENATO TAPAJÓS. O Estado de S. Paulo, 18 de agosto de 1977.

PRISÃO DE FICCIONISTA CONSTITUI FATO INÉDITO. O Estado de S. Paulo, 30 de julho de 1977.

PRISÃO DE TAPAJÓS: MAIS DOIS PROTESTOS. O Estado de S. Paulo, o 9 de agosto de 1977. PROCURADOR DENUNCIA TAPAJÓS. Jornal do Brasil, 30 de setembro de 1977. PROCURADOR QUER TAPAJÓS EM LIBERDADE. Folha de S. Paulo, 23 de agosto de 1977. SECRETÁRIO DE SEGURANÇA PÚBLICA LÊ ROMANCE, ACHA-O SUBVERSIVO E PRENDE AUTOR. Jornal do Brasil, 29 de julho de 1977.

STM ABSOLVE AUTOR DE FICÇÃO. O Estado de S. Paulo, 20 de outubro de 1978.

STM NEGA QUE LIVRO DE REENATO (sic) TAPAJÓS INCITE À SUBVERSÃO. Folha de $S$.

Paulo, 26 de outubro de 1978.

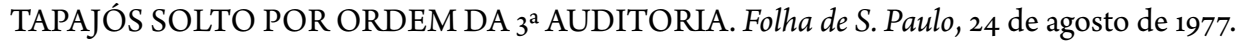


Livro de combate: $O$ caso Em câmara lenta e sua repercussão pública no contexto...

SOBRE O AUTOR

Mário Augusto Medeiros da Silva é sociólogo, com Mestrado e Doutorado em Sociologia (Universidade Estadual de Campinas). É professor e pesquisador do Departamento de Sociologia da Universidade Estadual de Campinas. Tem experiência na área de Pensamento Social, Intelectuais e Intelectuais Negros.

E-mail:mariomed@unicamp.br.

Recebido em 31 de março de 2017 e aprovado em 26 de abril de 2017. 